\section{TAP deficiency is also a cause of bronchiectasis}

We read with interest the recent bronchiectasis review by Whitters and Stockley. ${ }^{1}$

The authors provide a comprehensive overview of the changes in the immune response that might favour bacterial colonisation of the lower airways and in a second step initiate the vicious cycle leading to chronic inflammation and recurrent infections. Their description of the innate immune system in the lung includes antibacterial peptides, neutrophils and tolllike receptors. Although this is correct, Natural Killer (NK) cells might also be mentioned, as their role in the immune response to bacteria (besides their antiviral and antitumor functions) has been repeatedly documented. ${ }^{2} 3 \mathrm{NK}$ cells participate in innate immune defence mechanisms through (i) the release of cytotoxic granules containing, among others, the antibacterial factors granulysin, $\alpha$-defensins and cathelicidin, ${ }^{2}$ and (ii) cytokine production that stimulates both innate and adaptive immunity. In addition, they have immunoregulatory properties able to limit excessive immune responses. ${ }^{3}$ Thus, it is highly likely that NK cells are one of the actors participating in the pathogenesis of bronchiectasis. The same may hold true for the more recently discovered (non NK) innate lymphoid cells, but more work will be necessary to establish this.

Another important point of the review is the useful list of the causes of bronchiectasis in which transporter associated with antigen processing (TAP) deficiency is however missing. TAP proteins are crucial for peptide loading on newly synthesised Human Leukocyte Antigen (HLA) class I molecules, and the consequence of TAP deficiency is a very low cell-surface expression of these HLA class I molecules. ${ }^{4} 5$ Clinically, besides skin ulcers, the patients suffer from chronic bacterial infections of the upper and lower airways with bronchiectasis. ${ }^{4} 5$ Although the known cases of this immune deficiency are rare (around 30 patients reported in the literature), there might be much more, as the diagnosis of idiopathic bronchiectasis might be made in most instances without having checked for TAP deficiency (by staining of patients' peripheral blood mononuclear cells with an anti-HLA class I antibody which reveals by flow cytometry a very low expression level compared to healthy control donors, and/or the absence of HLA class I molecules by serotyping).

In our opinion, it is important to detect TAP deficiency as soon as possible in order to optimise the treatment of the patients, and thus it should be systematically included in the diagnostic algorithms applied to the exploration of chronic respiratory infections and bronchiectasis.

Jacques Zimmer, Marwan Sleiman, Aurélie Poli, Tatiana Michel, François Hentges

Laboratory of Immunogenetics and Allergology, CRP-Santé, Luxembourg-City, Luxembourg

Correspondence to Dr Jacques Zimmer, Laboratoire d'Immunogénétique-Allergologie, Centre de Recherche Public de la Santé (CRP-Santé), 84 Val Fleuri, Luxembourg L-1526, Luxembourg; jacques.zimmer@ crp-sante.lu

Contributors All the authors deserve criteria for authorship. They all read and approved the final version of the manuscript.

Funding The work of the F. Hentges lab is financed by the Luxembourgish Ministry of Health. MS is the recipient of a PhD AFR grant from the Luxembourgish National Research Fund (Fonds National de la Recherche).

Competing interests None.

Provenance and peer review Not commissioned; internally peer reviewed.

To cite Zimmer J, Sleiman M, Poli A, et al. Thorax 2013;68:490-491.

Received 27 November 2012

Accepted 17 December 2012

Published Online First 8 January 2013

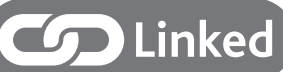

http://dx.doi.org/10.1136/thoraxjnl-2012-203138

Thorax 2013;68:490-491.

doi:10.1136/thoraxjnl-2012-203052 


\section{REFERENCES}

1 Whitters D, Stockley R. Immunity and bacterial colonisation in bronchiectasis. Thorax

2012;67:1006-13.

2 Souza-Fonseca-Guimaraes F, Adib-Conquy M, Cavaillon JM. Natural killer (NK) cells in antibacterial innate immunity: angels or devils? Mol Med 2012;18:270-85.

3 Horowitz A, Stegmann KA, Riley EM. Activation of natural killer cells during microbial infections. Front Immunol 2012;2:88.

4 Gadola SD, Moins-Teisserenc H, Trowsdale J, et al. TAP deficiency syndrome. Clin Exp Immunol 2000;121:173-8.

5 Zimmer J, Andres E, Donato L, et al. Clinical and immunological aspects of HLA class I deficiency. Q J Med 2005:98:719-27. 